\title{
How does Information Spread? A Study of True and Fake News
}

\author{
Sandeep Suntwal, Susan A. Brown, Mark W. Patton \\ University of Arizona \\ \{sandeepsuntwal, suebrown, mpatton\}@email.arizona.edu
}

\begin{abstract}
The intentional and non-intentional use of social media platforms resulting in digital wildfires of misinformation has increased significantly over the last few years. However, the factors that influence this rapid spread in the online space remain largely unknown. We study how believability and intention to share information are influenced by multiple factors in addition to confirmation bias. We conducted an experiment where a mix of true and false articles were evaluated by study participants. Using hierarchical linear modelling to analyze our data, we found that in addition to confirmation bias, believability is influenced by source endorser credibility and argument quality, both of which are moderated by the type of information - true or false. Source likeability also had a positive main effect on believability. After controlling for belief and confirmation bias, intention to share information was affected by source endorser credibility and information source likeability.
\end{abstract}

\section{Introduction}

The purpose of information is to empower consumers and help them make choices that have small or large impacts, such as selecting which television to buy or choosing the next government for their country. However, information varies in both quality and impact. In recent years, both intentional and nonintentional impacts of using social media platforms to spread misinformation have increased [1]. While news is defined as an account of current, real, and important events [2] that affect people [3], fake news is defined as an entire ecosystem of misinformation that includes sharing or spreading false information and the creating and sharing of disinformation [4]. Fake news has been used to refer to misinformed and disinformed news articles, hoaxes, rumors, parodies, incorrect editorials, incorrect facts, etc. This variety in purpose, channels, sources, and motivations makes it more difficult to understand its online spread [5]. Although yellow journalism in the print media and disinformation in the online domain has been around for years, political fake news made headlines during the 2016 US Presidential election and became a worldwide discussion after allegations of intervention by foreign actors were made. The office of the director of US national intelligence released a declassified report [6] about foreign intervention in the elections. With several more elections now lined up across the world, and the two largest democracies going into elections in 2019 and 2020 respectively, fake news is likely to increase its influence and impact on how over one billion voters exercise enfranchisement in these two countries alone. Media studies have also shown that three months before an election, the top 20 fake information articles exceeded the top 20 stories from mainstream media outlets in terms of users sharing, reacting, and commenting on the articles [7]. All this motivates us to investigate this issue further.

\section{Prior Theory and Research}

As fake news has broad definitions and purposes, understanding it is emerging as a significant research challenge. Technical and behavioral scientists are looking at this problem from multiple perspectives. Behavioral scientists have made significant progress in understanding how readability, placement of titles, etc. affect belief. However, a key aspect of fake news is its ability to persuade readers that it is true. The Elaboration Likelihood Model (ELM) is a key theory for understanding persuasive communication better. The two key routes of ELM, the central and the peripheral routes, explain how persuasive communication affects both individual belief and intention to share.

\subsection{Fake News}

As mentioned, fake news has been used broadly and refers to a range of items, which makes it a difficult issue to address [5]. Identifying the purpose, channel, source, and propagators can help us better grasp its dimensions.

Key purposes for spreading fake news include but are not limited to satire or parody/humor [8], financial gain from promoting fake 'sponsored' news stories supporting products [9], bloggers looking for large audience to gain views and advertising revenue [10], and election manipulation [11]. Fake news has been used to manipulate public sentiment and cause public unrest [12] through internal [13] and foreign intervention [6]. In some cases, fake news is created to garner support or drive opposition towards controversial topics (e.g., welfare, abortion, gun control) [14].

There are two broad areas of research on Fake news: technical and behavioral. Technical focuses on detecting 
fake news automatically using models and linguistic cues [15] while behavioral research focuses on human aspects like belief, attitude, intentions, etc. Given our focus is on belief and intention to share, we anchor on behavioral research.

In the behavioral domain, recent studies rooted in different theories are looking at the issue of fake news from multiple angles. The Theory of Engagement demonstrated readability improved source credibility, but source credibility had no impact on active or passive propagation [17]. In [17], participants collected and shared cyber news on a social engagement platform (Slack.com). However, the study used 'source' to refer to both a person or an organization, which can lead to reader confusion between the person sharing the item versus the portal sharing it.

Reputation theory has shown most readers of fake news are affected by confirmation bias [18]. In their experiment, Kim and Dennis [18] evaluated the effects of story format, source ratings, and source reliability on believability by using headlines. They found that headlines in story format were less believable than headlines in news format. They also found source ratings had a significant positive effect on believability. Another key finding was the significant positive effect of confirmation bias on believability, and believability had a further positive effect on activities like reading, commenting, and sharing.

However, the fake news ecosystem produces a lot of textual content and uses additional techniques to persuade the reader, raising the need to understand the role of persuasive communication believability in information. Based on the epistemology of testimony, the relationship between an individual's news verification behaviors and intention to share was explained [19]. In this study, it was found that intention to share led to higher verification behaviors.

However, we need to understand what leads to intention to share in the first place. Using ELM as a base, business fake news was found to have low variance in content and high negativity, taking a peripheral route [20]. They calculated the entropy of content in 80 comparable business news articles, finding true news contains more information than fake news. However, the impact on readers is still not understood.

\subsection{Elaboration Likelihood Model (ELM)}

ELM is a generic framework for arranging, classifying, and understanding the latent success of persuasive communications and consequently communication driven changes in individual attitude [21][22]. Based on the personal relevance of a message to the user, ELM defines two routes taken by the persuasive message to induce attitude change in an individual [22]. When personal relevance is high, the route indi- viduals prefer is the central route. Using this route, a person carefully and thoughtfully considers the true merits in support or contradiction of an opinion the message presented, focusing on argument clarity [22]. Argument clarity can be defined as cogent versus weak arguments regarding a topic.

Personal relevance in the context of fake news refers to topics users care about such as gun rights, pro-life/prochoice, immigration, vaccination, etc. irrespective of their stance on the issues. Some studies that have focused on linguistic content of fake news have shown they contain more repetitive content and rely on other peripheral techniques [16], while having lower variance in content [20] indicating their greater reliance on peripheral cues relative to true news. When personal relevance to the message is low, individuals take the alternative peripheral route. Using this route, a person does not scrutinize the true merits of the message and instead uses external cues like looks, quantity, etc. [22] to judge the information. External cues can be further divided into two categories: message cues and source cues. Peripheral message cues include features like number of arguments in a message, i.e., length of the message, choosing between music over attributes of the product in an advertisement [23], or visual salience of the message or advertisement [24]. These can also be treated as peripheral message cues in the ELM and therefore influence a person's opinion. Peripheral source cues include users' trust and likeability for the source, either a person endorsing the message or the organization presenting it. The effects of persuasion through the two routes of ELM is an understudied phenomenon in the context of fake news.

\subsection{Confirmation Bias and Belief}

The human nature of overlooking evidence against a belief of uncertain truth while still supporting the belief is confirmation bias [25]. Motivation and cognitive factors are both responsible for confirmation bias and mediate the effects of one another [25]. In Wason's 2-4-6 triplet numbers hypothesis task [26] when hypothesized that the series was ascending numbers, users failed to put forth alternatives that might disprove this hypothesis. This result confirmed people's bias towards choosing evidence that would support their own hypothesis by looking for confirmatory evidence or ignoring falsifiability of a hypothesis completely. Confirmation bias can affect individuals interacting with information in several ways. In their study to understand a computer-mediated counter argument system, Huang et al. [27] measured confidence level in individuals with confirmation bias, before and after an interruption by the system. In the fake news domain, Kim and Dennis [18] measure perceived believability of individuals with confirmation bias in a news article. They found confirmation bias towards a headline in an online 
poster had a significant positive effect on belief in the poster's topic.

\subsection{Sharing information on social media}

Social media platforms have provided users with several features such as Likes, Shares, Retweets, Forwarding, etc. that enable sharing or spreading of information. A recent survey by Pew Research [28] showed $67 \%$ percent of Americans receive some form of news from social media and $71 \%$ have seen some made up news either sometimes or often. Active users on social media have been classified as 'Produsers'individuals who do not simply produce or use the information on social media but play a dual role where they share information created by others as their own [29][30]. Presenting oneself as a source of information serves individuals psychologically and enables them to act as gatekeepers of information [31]. In their work, Oeldorf-Hirsch and Sundar [30] suggest that, on social media, individuals value the involvement of their network members, seeking to keep their audience interested and having a sense of influence, hence driving more engagement. Therefore, people may tend to share information on social media and more so when it comes from the sources they follow or the groups of which they are members.

\subsection{Literature Review Summary}

In summary, prior work provides a foundation on which to build, yet several questions remain.

Behavioral models aim to explain individual behaviors to better understand the spread of fake news based on deep-rooted theories. However, there are gaps in the literature. First, most studies relied on news snippets and not complete (real-looking) news articles. An actual news article (True or Fake) may help us better understand what makes news believable beyond the headline. Second, the roles of sources and endorsers were not strongly distinct in these studies. This can cause confusion if the user dislikes the news source but likes the actual endorser, or vice versa. Third, several studies showed what believability leads to and/or impacts but not what led to the believability. Fourth, there is a need to mitigate partisan biases in these studies. We aim to build on these studies by addressing these gaps.

\section{Theory Development and Model Con- ceptualization}

\subsection{What makes information believable?}

Belief and confirmation bias are strongly tied together [26]. Several studies have shown the significant effect of confirmation bias on believability [18]. We control for confirmation bias in the proposed hypotheses from $1 \mathrm{~A}$ to $1 \mathrm{~F}$.

Confirmation bias is driven by an individual's stance on and affinity for a topic, but beyond confirmation bias there are several other underlying factors that convince consumers of the veracity of online information. ELM defines central and peripheral routes taken by a persuasive message to induce attitude change [21]. Peripheral source cues tell us the attributes of the source from whom the message is coming. When information is shared online, there are two important sources that individuals can look at explicitly, the person or organization sharing/endorsing the information and the entity hosting/producing the information. In the context of sociopolitical information individuals sharing or endorsing information can be important politicians and opinion makers such as Hillary Clinton, Donald Trump, or organizations like the National Rifle Association (NRA) or Planned Parenthood.

Since many of these endorsers do not create the content they selectively share or endorse, the information that they endorse is often produced by another entity. Content producers are typically either mainstream media like CNN, Fox, CNBC, or non-mainstream media outlets such as Breitbart. The degree of belief in information is influenced by the reputation or credibility of the source [32]. We argue that beyond confirmation bias, information endorsed by key individuals or influencers and/or created by news outlets whom the users perceive to have great credibility will be more believable. Consumers will also find information less believable if they don't find the sources and endorsers credible. Therefore, we propose:

Hypothesis 1A: Source-Endorser credibility will be positively associated with belief.

Fishbein and Ajzen [33] define belief as the internalized likelihood of a bond between the social object of belief and another attribute or social object. In persuasion literature, source likeability refers to the ability of the source to create a pleasant and hedonistic perception of the source [34][35]. It has been compared to source attractiveness in existing literature [36]. Source likeability is a visual cue and plays a significant role in the peripheral route. We believe that if a source is attractive i.e., it presents the news in an attractive way, then the reader will be positively influenced regarding the information presented in the article. Therefore, like source endorser credibility, the look and feel of an online site measured as source likeability can influence an individual's belief. Therefore, we propose:

Hypothesis 1B: Source likeability will be positively associated with belief.

Argument quality refers to perceived logicalness of an article and is part of the central route of the ELM. It focuses on whether the article's arguments were perceived as logical. It aims to make sure that beyond look and feel, 
and the source and endorser, the quality of the arguments presented in the article played a role in convincing the reader. Overall, if argument quality is good, people will be positively influenced to believe the information presented. Well written arguments in any article make it difficult to discern fake information from true information. Therefore, we propose:

Hypothesis 1C: Argument quality will be positively associated with belief.

Source endorser credibility and source likeability are a part of the peripheral route. Fake information peddlers prefer the peripheral route as it is easier to convince consumers of information when they are not paying attention to the actual argument quality of the information. Therefore, we hypothesize that source endorser credibility and source likeability (peripheral route) affect believability more for fake news than true news. Hence, we propose the following hypotheses where the type of news acts as a moderator. Therefore, we propose:

Hypothesis 1D: News type will moderate the relationship between the source-endorsers' credibility and belief such that true news will increase the strength of the relationship between source-endorser credibility and belief in the information presented to the consumer of news.

Hypothesis 1E: News type will moderate the relationship between the source likeability and belief such that true news will increase the strength of the relationship between source likeability and belief in the information presented to the consumer of news.

Unlike the peripheral route, the central route is strongly message driven. A key message cue used for assessing information while taking the central route is quality of the information presented. A high perceived argument quality can deceive consumers of information more than peripheral factors like credibility or likeability. However, existing studies have shown that fake news generally does not contain high argument quality. Therefore, we propose:

Hypothesis 1F: News type will moderate the relationship between the argument quality and belief such that true news will increase the strength of the relationship between argument quality and belief in the information presented to the consumer of news.

\subsection{What drives intention to share infor- mation?}

Confirmation bias affects individuals when they believe in information put forth to them on social media platforms. Previous studies have shown that having high prior beliefs on ideological issues also leads to confirmation bias [37]. Ideological strength can be explained as how strongly one identifies with a political ideology [38]. Combining ideological strength with importance and stance, a true indicator of confirmation bias can be measured. Drawing on the Theory of Planned Behavior (TPB) [39] and knowledge sharing motivation model [40] we believe the importance assigned to an issue, stance, and ideological strength measured as confirmation bias is a key indicator of a person's intention to share information. Therefore, we hypothesize:

Hypothesis 2A: Confirmation bias is positively associated with individuals' intention to share information online.

Intention can be defined as an individual's locus on a subjective probability dimension which involves a relation between that individual and a given action [33]. Behavioral intention specifically refers to the probability an individual will perform some behavior [33]. Belief in a social object sets the foundation for the formation of attitude towards the social object [33]. It has been argued in the literature that the more favorable stand a person has towards some social object, in our case higher belief towards the news article, the more the individual will intend to perform positive behavior [33], which in our study is to have an intention to share and spread the article. Therefore, we propose:

Hypothesis 2B: Controlling for confirmation bias, belief is positively associated with individuals' intention to share information online.

When information comes from a source you follow unidirectionally, intention to share is higher [41]. In a unidirectional relationship on social media i.e. a person following an influencer, the likelihood to share information is higher. The percentage of bidirectional relationships is low on social media platforms. The top accounts on social media platforms are the individuals or entities we consider as endorsers in our study. Based on Wikipedia's list of 10 top followed accounts on twitter, we calculated that these accounts had 860 million followers cumulatively while they followed only 0.77 million accounts showing a high discrepancy between unidirectional and bidirectional relationships. This implies intention to share will be high for many individuals. Thus, we propose:

Hypothesis 2C: Controlling for confirmation bias and belief, source endorser credibility is positively associated with individuals' intention to share information online.

Source likeability is also a cue [21] of the peripheral route which refers to the source's ability to create a likeable perception [34]. We refer to source likeability as how likeable, professional, and reliable the site hosting the information is. Past studies in advertisement literature have indicated that a likeable source increases the viewer's attention towards the ad and generates positive feelings towards brands, leading to increased purchasing intention and likelihood [35][47]. We believe, similarly, source likeability is critical in determining if information from the web page will be shared further. Therefore, we propose: 
Hypothesis 2D: Controlling for confirmation bias and belief, source likeability is positively associated with individuals' intention to share information online.

When using the central route, consumers of information evaluate the merits of information presented to them. Argument quality is a message cue and forms a part of the central route of the ELM [21]. Produsers are looking for content with strong defensible arguments to share on social media [29][30]. Therefore, selecting information articles with perceived strong argument quality is an important factor while sharing information. Stronger argument quality beyond belief and confirmation bias will lead to higher intention to share information. Therefore, we hypothesize:

Hypothesis 2E: Controlling for confirmation bias and belief, argument quality is positively associated with individuals' intention to share information online.

Individuals believe in fake news due to several factors like confirmation bias, source cues, message cues, etc. as hypothesized earlier. Therefore, when compared to true news, there is a greater likelihood of retweeting or sharing fake news by individuals [5]. Individuals overlook network and individual factors which favor truth [5]. This indicates that individuals may be unable to overcome confirmation bias and their beliefs, sharing more fake news than true news. We hypothesize, that there is a significant difference between the intentions to share fake or true information and this relation is more positive for fake news than news. Therefore, we hypothesize:

Hypothesis 2F: Controlling for confirmation bias and belief, individuals will have greater intention to share fake news.

\section{Research Methodology}

\subsection{Scale Development}

We conducted an extensive literature review to develop the measurement scales for the constructs in the study. To understand social, political, and technological backgrounds of the participants, the survey instrument began with questions regarding participant demographics.

We captured social indicators such as age groups, gender, and political preferences. Using a list of political parties that participated in the 2016 Presidential election [42] we selected parties whose candidates won at least $0.5 \%$ of the popular votes in total. We had 5 political choices - democrat, green, independent, libertarian, and republican - representing $99.16 \%$ of the presidential popular vote. An additional item indicating no political preference was added. We measured political preferences such as political party alignment and alignment strength. The first two questions asked participants to indicate which ideology they aligned with most, followed by how strongly they identified with the political party they selected. Following this section, we measured social media and technology usage behaviors.

\subsection{Participants}

For the primary study, we developed and administered a web-based survey to students in a large southwestern research university. A total of 327 participants completed the survey. We applied strict filtering criteria for data cleanup. As identified in the pilot test, a minimum cutoff of 16.67 minutes was applied for filtering and removing incomplete responses and participants paying inadequate attention. We measured the amount of time each participant spent between opening a news article and answering questions. We retained 8 records that were more than 80 percent complete but not 100 percent complete for understanding the demographics better. In total, 250 records were selected. We removed outliers where the same option was marked continuously for all the answers. We also used attention check questions for each article, and all retained participants answered these correctly. The attention check questions appeared in a random order for article that was displayed. The final responses in the study varied by gender, partisan choices, and other demographic indicators. The participant population was composed primarily of millennials. As the highest age group users of social media [43], millennials represent a considerable sample of the general population.

\subsection{Scenario Design}

We asked participants to read four articles and measured independent and dependent variables. Belief and intention to share were the dependent variables. Central route, peripheral route, confirmation bias, and individual characteristics were the independent variables. Each scenario consisted of four news articles. All news articles, both true and fake, were checked for veracity using news checking websites like snopes.com and politifact.com. In some cases, fake news stories were generated from true news stories by news outlets such as cnn.com, cnbc.com, fox.com, etc. through manipulation of the headlines, dates, and content to make them look as close as possible to true news. These were vetted by a panel of judges for correctness. Creating look-alike and modified web pages is a common tactic often employed by fake news peddlers [15]. The individual or group endorsing the information has a significant influence on how information is received by people [44]; hence, we added a known endorser of conservative or liberal ideology to each article.

\subsection{Procedure}

The participants were presented a link directing them to a web site created for this study. Each participant was shown four articles, fake and true, conservative and liber- 
al, from a pool of 16. After each article was presented, measurements were captured. To ensure that the participants were not influenced by prior knowledge of the article, we asked if they had read this story before. If the user had read the article, they were presented a different one. We adapted the source credibility construct [45][46] for measuring source-endorser credibility of individuals or groups, and the Websites or News portals hosting the news. Next, we measured confirmation bias by adding a political ideological strength item. We then measured the central and peripheral route constructs of the ELM. As a part of our experiment design, we selected issues that would have high personal relevance to readers of pro-left, center, or pro-right political alignments. Each of these issues had both a random fake news and true news article associated with it. So any user would get two issues that would be relevant to a pro-left reader or a pro-right reader. The participants were asked to report belief in the information presented to them. Belief was measured using a two-item Likert scale. We measured our second dependent variable, intention to share, using a two item 7- point Likert scale adopted and modified from intention to share knowledge [47] and repurchase intention [48] surveys. All scales, definitions and demographics summary have been reported in Appendix (section 7)

\section{Instrument Validation}

\subsection{Reliability and Validity Checks}

First, we analyzed the measurement properties of our model's constructs: Source-Endorser credibility, argument quality, source likeability, belief, and intention to share by following standard procedures. Table 1 shows the internal reliability checks. We examined each individual item by loading and average variance extracted (AVE) for each construct to ensure reliability and convergent validity. AVE values for the constructs were higher than the recommended cutoff value of 0.50 [49]. Cronbach's alpha value greater than 0.7 has been recommended in the literature for established studies and greater than 0.6 for exploratory studies [50][51]. Cronbach's alpha values were higher than 0.7 for all the constructs. The composite factor reliability values were greater than the recommended threshold of 0.7 for all constructs. Thus, reliability is established. Table 2 shows correlations and square root for each construct across the diagonal, the square root of AVE (diagonal values) was greater than the correlation values with other constructs in the model. Discriminant validity [50] was supported by these results. All item loadings were greater than 0.60 meeting recommended levels for exploratory studies [52]. The model's fit indices were satisfactory, the SRMR
$(.06<=.09)$, RMSEA $(.08<=.08)$ and CFI $(95.9>=95 \%)$ were at acceptable levels [52]. To check for common method bias, we carried out the marker-variable analysis [53]. To adjust correlations between the main variables of our study, we utilized "Public self-awareness" [54][55] as a theoretically unrelated variable measured by the question- "I have been concerned about the way I've responded and presented myself to my online social network".

\begin{tabular}{|l|l|l|l|}
\hline Var. & \multicolumn{1}{|c|}{ AVE } & CA & CR \\
\hline SEC & 0.77 & 0.90 & 0.90 \\
\hline SL & 0.66 & 0.83 & 0.85 \\
\hline AQ & 0.63 & 0.75 & 0.76 \\
\hline BE & 0.63 & 0.71 & 0.76 \\
\hline IS & 0.87 & 0.93 & 0.93 \\
\hline
\end{tabular}

Table 1. Internal Reliability Checks

\begin{tabular}{|l|l|l|l|l|l|}
\hline & SEC & SL & AQ & BE & IS \\
\hline SEC & $\mathbf{0 . 8 8}$ & & & & \\
\hline SL & 0.60 & $\mathbf{0 . 8 1}$ & & & \\
\hline AQ & 0.74 & 0.52 & $\mathbf{0 . 8 0}$ & & \\
\hline BE & 0.72 & 0.50 & 0.73 & $\mathbf{0 . 8 0}$ & \\
\hline IS & 0.40 & 0.34 & 0.40 & 0.43 & $\mathbf{0 . 8 4}$ \\
\hline
\end{tabular}

Table 2. Correlations between Factors

\subsection{Hierarchical Linear Modelling (HLM)}

As the variables were measured repeatedly within and between students, we analyzed our data using HLM. HLM also accounts for the non-independence (within students in our case) between observed data. We calculated the interclass correlation coefficient (ICC) scores for the null models and the random effects model using participant as the random effect.

\subsection{HLM Model Testing}

The factor scores from the survey were used to analyze the level-1 (within participants) and level-2 (between participants) effects. All the predictors were group mean centered to avoid any multicollinearity issues, and model estimation was performed using restricted maximum likelihood method. The main model contained the main, control, and interaction variables for testing the hypotheses.

\subsubsection{Results}

We found support for most of our hypotheses and some surprising counterintuitive results as well. Figure 1 shows the results.

Hypotheses 1A, 1B, 1C, and 1F were supported in our study while Hypothesis 1D was statistically significant but in the opposite direction and thus not supported, and 1E was neither significant nor supported. Next, we tested our hypotheses for intention to share. Hypotheses $\mathbf{2 A}, \mathbf{2 B}$, 
2C, 2D were supported in our study while $\mathbf{2 E}$ and $\mathbf{2 F}$ were not significant statistically and thus not supported.

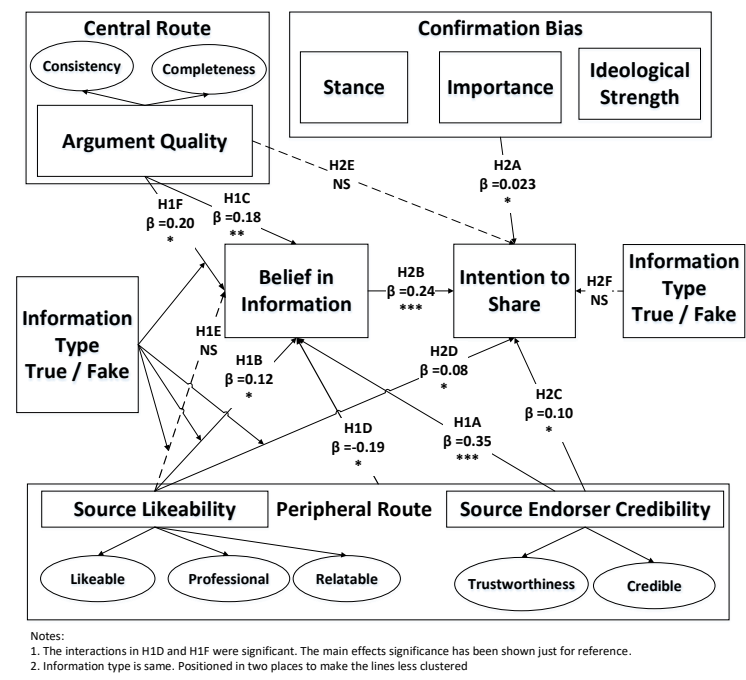

Figure 1. Model Result

\subsection{Discussion and conclusion}

This work makes several contributions in understanding both belief and intention to share information online. Keys to understanding the spread of information online included the type of news, sourceendorser credibility, source likeability, confirmation bias, and argument quality.

After controlling for confirmation bias, we found source-endorser credibility affected belief positively (H1A) indicating that beyond confirmation bias, the credibility of the source along with the endorser played a significant role in predicting belief in information. When participants believed that the source and/or the endorser had high credibility, they were more likely to believe the information presented.

Testing for the effect of source likeability after controlling for confirmation bias, we found that the look and feel of the web page that was displaying the information positively affected belief (H1B).

Argument quality, after controlling for confirmation bias, positively affected belief (H1C). If individuals perceived the argument quality to be high, they were more likely to believe the information they were consuming.

The two-way interaction between News Type (true or false) and source-endorser credibility (peripheral route of the ELM) was significant (H1D). This indicated that true information with an average source endorser credibility score will have 0.19 units less belief than all fake news in our study. For the same level of source endorser credibility, people were more likely to believe a fake news story than a true news story. This result is critical as it indicates that the peripheral route contributes to belief in fake information. This finding also supports the argument that the peripheral route helps in the spread of fake information. It is easier for popular sources and endorsers to make individuals believe in a false story compared to truth.

There was no two-way interaction between news type (true or false) and source likeability (H1E).

The significant two-way interaction between news type (true or false) and argument quality (H1F) indicates that true information with an average argument quality score will have 0.20 units higher belief than fake news with an equivalent argument quality score. So, for the same level of argument quality, people are more likely to believe in true news than fake news. True news finds it easier to convince a person compared to fake news for the same level of argument quality.

The results for intention to share provide important insights into understanding the spread of information online. Confirmation bias positively affected intention to share $(\mathrm{H} 2 \mathrm{~A})$, if people agree with the stance of the article and find the issue important enough, they have a higher intention to share. After controlling for confirmation bias, we found support for our hypothesis (H2B) that belief positively affected intention to share. Next, after controlling for confirmation bias and belief, we found sourceendorser credibility positively affected intention to share (H2C). We also found that after controlling for confirmation bias and belief, source likeability affected intention to share positively (H2D). Articles from professional looking websites or news portals have a higher likelihood for being shared.

We found that after controlling for confirmation bias and belief, the effect of argument quality was not statistically significant $(\mathrm{p}=0.38)$ on intention to share $(\mathrm{H} 2 \mathrm{E})$. This result is important and indicates that although believability of the article goes up as the argument quality increases, readers may still not be inclined to share it. After controlling for confirmation bias and belief, the type of information (true or fake) did not have a statistically significant effect on intention to share. Although participants believed more in true news than fake news, their intention to share was not completely driven by the news being true or fake. This also explains that belief and confirmation bias predict intention to share and do not really depend on the nature of the news itself.

\subsection{Limitations}

First, this was not an exhaustive sample representing the entire population that votes or uses social media. We had several participants who were first-time voters or who had never voted at all. Second, we acknowledge that these are not the only factors that affect believability and intention to share. Several more behavioral factors related to persuasion [5] need to be investigated in the future. We 
also aim to conduct a mixed methods study [57] using the qualitative data that we have collected from participants of our study to better understand how they reached their conclusions. More work is needed to understand how individuals take the central or peripheral route of persuasion depending on the news type when they are not aware if the news is true or false.

\subsection{Implications}

\subsubsection{Theoretical Implications}

Our study makes several theoretical contributions. Using the theory of persuasion, we explain factors affecting believability and intention to share. Both are required for understanding how information spreads online. We show that stopping at confirmation bias is insufficient to explain the spread of fake news. Several other behavioral components play a role. In our study, measurement for confirmation bias itself was extended to include ideological strength, and after controlling which, we found several factors of the ELM to significantly affect belief and intention to share.

Beyond this, extending confirmation bias to include ideological strength can enhance our understanding of digital tribalism [58]. Second, although attention has been paid to intention to share, it is important to understand belief in order to fully understand intention. We show belief positively influences intention. It is important to consider belief as a predictor of intention to share for related future work. The key theoretical implications can be understood from the way the two components of central and peripheral routes interacted with news type to predict belief. Central route plays a role in high relevance situations.

Third, to the best of our knowledge, we are the first to explain intention to share fake and true information using ELM based on persuasion theory. We show that confirmation bias and belief affect intention, however, after controlling for these two factors, the central route did not have a significant effect, only the peripheral route affected intention to share significantly. Previous studies have shown peripheral cues like source likeability affecting intention to share private information [59]. We extend those findings to show that peripheral cues generally impact intention to share information.

\subsubsection{Practical Implications}

Our findings have implications beyond belief and intention to share. We believe it is important to educate people about the implications of sharing fake news. Like several other cyber threat mitigation strategies, we recommend training individuals to identify true or fake information. Helping individuals identify reliable endorsers may also help, while developing a good reputation may be an incentive for endorsers as well. Further, these findings can be applied to various types of persuasive communications in organizations, on dark web, etc. to understand what leads to belief and trust in information there. We can use the results from this study to answer research questions such as, does source likeability affect belief in the content on such web sites?

\section{Conclusion}

Fake news is a huge challenge. Content on the internet quickly reaches people at scale, allowing online events to reach a wider audience with a great impact. Studies have found humans are directly behind the spread of fake news. In this study, we conducted an experiment to understand what factors of persuasive communication affect humans' belief in and intention to share information online. We found several factors including source and endorser credibility, source likeability, argument quality, etc. to be significantly affecting belief. Argument quality had no significant effect on intention to share indicating true or fake news were equally likely or unlikely to be shared. The silver lining is that we found consumers were no more likely to share fake news than true news.

\section{Appendix}

\begin{tabular}{|l|l|c|}
\hline Indicator & Statistics & $(\%)$ \\
\hline \multirow{4}{*}{ Gender } & Male & 59.60 \\
\cline { 2 - 3 } & Female & 40.0 \\
\cline { 2 - 3 } & Wish not to identify & 0.40 \\
\hline \multirow{4}{*}{ Partisanship } & Democrat & 19.20 \\
\cline { 2 - 3 } & Green & 0.0 \\
\cline { 2 - 3 } & Independent & 18.40 \\
\cline { 2 - 3 } & Libertarian & 6.0 \\
\cline { 2 - 3 } & Republican & 34.80 \\
\cline { 2 - 3 } Hours spend & No preference & 21.60 \\
\cline { 2 - 3 } reading news & Less than 1 hour & 29.20 \\
\cline { 2 - 3 } & 1-3 Hours & 44.40 \\
\cline { 2 - 3 } & 3-5 Hours & 16.0 \\
\cline { 2 - 3 } & More than 5 Hours & 8.40 \\
\cline { 2 - 3 } & I don't read news online & 2.0 \\
\hline \multirow{4}{*}{$\begin{array}{l}\text { Top Pre- } \\
\text { ferred News } \\
\text { medium }\end{array}$} & Newspaper & 7.20 \\
\cline { 2 - 3 } & Television & 75.60 \\
\cline { 2 - 3 } & Online/Computer & 17.20 \\
\hline
\end{tabular}

Table 3. Summary of Demographics

\begin{tabular}{|l|l|}
\hline Name & Definition \\
\hline $\begin{array}{l}\text { Source- } \\
\text { endorser } \\
\text { credibility }\end{array}$ & $\begin{array}{l}\text { SEC consists of combined expertise and } \\
\text { trustworthiness of the news portal (source) } \\
\text { and endorser (celebrity or organization) } \\
\text { [50][51] }\end{array}$ \\
\hline $\begin{array}{l}\text { Source like- } \\
\text { ability }\end{array}$ & $\begin{array}{l}\text { Likeability of overall content and a web- } \\
\text { site's look and feel [60] }\end{array}$ \\
\hline $\begin{array}{l}\text { Argument } \\
\text { Quality }\end{array}$ & $\begin{array}{l}\text { Perceived completeness and consistency } \\
\text { [50][51] }\end{array}$ \\
\hline $\begin{array}{l}\text { Confirma- } \\
\text { tion bias }\end{array}$ & $\begin{array}{l}\text { Self-reported affinity value that any indi- } \\
\text { vidual had towards the news article [18] }\end{array}$ \\
\hline Belief & $\begin{array}{l}\text { Perceived believability of the news article } \\
\text { [18] }\end{array}$ \\
\hline
\end{tabular}




\begin{tabular}{|c|c|}
\hline $\begin{array}{l}\text { Intention to } \\
\text { share }\end{array}$ & $\begin{array}{l}\text { Adapted from intention to share } \\
\text { knowledge and repurchase intention } \\
{[52][53]}\end{array}$ \\
\hline ID & Definition \\
\hline CB1 & $\begin{array}{l}\text { I find the information in this article to be } \\
\text { important }\end{array}$ \\
\hline CB2 & $\begin{array}{l}\text { I agree with the overall stance of this arti- } \\
\text { cle }-3 \text { to } 3\end{array}$ \\
\hline CB3 & $\begin{array}{l}\text { how strongly do you identify with the } \\
\text { statement - I am a "Democrat", etc. (1-7) }\end{array}$ \\
\hline AQ1 & $\begin{array}{l}\text { The information provided in the article } \\
\text { feels complete }\end{array}$ \\
\hline AQ2 & $\begin{array}{l}\text { The information provided in the article is } \\
\text { consistent }\end{array}$ \\
\hline SEC1 & $\begin{array}{l}\text { The Web site publishing the article is cred- } \\
\text { ible }\end{array}$ \\
\hline SEC2 & $\begin{array}{l}\text { The individual sharing the information the } \\
\text { article is trustworthy }\end{array}$ \\
\hline SEC3 & $\begin{array}{l}\text { The individual sharing the information the } \\
\text { article is credible }\end{array}$ \\
\hline SL1 & $\begin{array}{l}\text { This news Web page looks professional } \\
\text { and neat }\end{array}$ \\
\hline SL2 & $\begin{array}{l}\text { This news Web page provides content I } \\
\text { like / enjoy reading }\end{array}$ \\
\hline SL3 & $\begin{array}{l}\text { This news Web page provides me with all } \\
\text { the information I need related to the topic }\end{array}$ \\
\hline IS1 & $\begin{array}{l}\text { I will share this article online from my } \\
\text { social media account }\end{array}$ \\
\hline IS2 & $\begin{array}{l}\text { I will continue to share similar articles } \\
\text { online in the future }\end{array}$ \\
\hline BE1 & How believable do you find this article? \\
\hline BE2 & $\begin{array}{l}\text { Overall, I find this article highly improba- } \\
\text { ble. (RC) }\end{array}$ \\
\hline
\end{tabular}

Table 4. Construct definition and measures

\section{References}

[1] World Economic Forum (2018). Digital Wildfires. http://reports.weforum.org/global-risks-2018/digitalwildfires/

[2] Kershner, James W. 2005. The Elements of News Writing. Boston, MA: Pearson Allyn and Bacon.

[3] Richardson, Brian. 2007. The Process of Writing News: From Information to Story. Boston, MA: Pearson.

[4] Wardle, Claire. 2017. "Fake News." It's Complicated. https://medium.com/1st-draft/fake-newsits-complicatedd0f773766c79.

[5] Vosoughi, S., Roy, D., and Aral, S. (2018). The spread of true and false news online. Science, 359(6380), 1146-1151.

[6] Office of the Director of National Intelligence, Background to "Assessing Russian Activities and Intentions in Recent US Elections": The Analytic Process and Cyber Incident Attribution (2017), available at https://www.dni.gov/files/documents/ICA_2017_01.pdf [7] Silverman, C. 2016. "This Analysis Shows How Viral Fake Election News Stories Outperformed Real News on Facebook". BuzzFeed News. 16 November 2016.

[8] Colletta, L. (2009). Political satire and postmodern irony in the age of Stephen Colbert and Jon Stewart. The Journal of Popular Culture, 42(5), 856-874.
[9] Farsetta, Diane, and Daniel Price. 2006. Fake TV news: Widespread and undisclosed Center for Media and Democracy [10] Subramanian, S. 2017. https://www.wired.com/2017/02/veles-macedonia-fake-news/

[11] Allcott, H., and Gentzkow, M. (2017). Social media and fake news in the 2016 election. Journal of Economic Perspectives, 31(2), 211-36.

[12] Khaldarova, I., and Pantti, M. (2016). Fake news: The narrative battle over the Ukrainian conflict. Journalism Practice, 10(7), 891-901.

[13] Balmas, M. (2014). When fake news becomes real: Combined exposure to multiple news sources and political attitudes of inefficacy, alienation, and cynicism. Communication Research, 41(3), 430-454.

[14] Starbird, K. (2017, May). Examining the Alternative Media Ecosystem Through the Production of Alternative Narratives of Mass Shooting Events on Twitter. In ICWSM (pp. 230-239).

[15] Conroy, N. J., Rubin, V. L., and Chen, Y. (2015). Automatic deception detection: Methods for finding fake news. Proceedings of the Association for Information Science and Technology, 52(1), 1-4.

[16] Horne, B. D., and Adali, S. (2017). This just in: fake news packs a lot in title, uses simpler, repetitive content in text body, more similar to satire than real news. arXiv preprint arXiv:1703.09398.

[17] Maasberg, M., Ayaburi, E., Liu, C., and Au, Y. (2018). Exploring the Propagation of Fake Cyber News: An Experimental Approach.

[18] Kim, A., and Dennis, A. R. (2017). Says Who?: How News Presentation Format Influences Perceived Believability and the Engagement Level of Social Media Users.

[19] Torres, R., Gerhart, N., and Negahban, A. (2018, January). Combating Fake News: An Investigation of Information Verification Behaviors on Social Networking Sites. In Proceedings of the 51st Hawaii International Conference on System Sciences.

[20] Osatuyi, B., and Hughes, J. (2018, January). A Tale of Two Internet News Platforms-Real vs. Fake: An Elaboration Likelihood Model Perspective. In Proceedings of the 51st Hawaii International Conference on System Sciences.

[21] Petty, R. E., \& Cacioppo, J. T. (1986). The elaboration likelihood model of persuasion. In Communication and persuasion (pp. 1-24). Springer, New York, NY.

[22] Petty, R. E., Cacioppo, J. T., and Goldman, R. (1981). Personal involvement as a determinant of argument-based persuasion. Journal of personality and social psychology, 41(5), 847.

[23] Gorn, G. J. (1982). The effects of music in advertising on choice behavior: A classical conditioning approach. The Journal of Marketing, 94-101.

[24] Borgida, E., and Howard-Pitney, B. (1983). Personal involvement and the robustness of perceptual salience effects. Journal of Personality and Social Psychology, 45(3), 560.

[25] Nickerson, R. S. (1998). Confirmation bias: A ubiquitous phenomenon in many guises. Review of general psychology, 2(2), 175-220.

[26] Wason, P. C. (1960). On the failure to eliminate hypotheses in a conceptual task. Quarterly journal of experimental psychology, 12(3), 129-140.

[27] Huang, H. H., Hsu, J. S. C., and Ku, C. Y. (2012). Understanding the role of computer-mediated counter-argument in countering confirmation bias. Decision Support Systems, 53(3), 438-447. 
[28] Pew Research (May 2019) https://www.journalism.org/2019/06/05/many-americanssay-made-up-news-is-a-critical-problem-that-needs-to-befixed/

[29] Bruns, A., Highfield, T., and Lind, R. A. (2012). Blogs, Twitter, and breaking news: The produsage of citizen journalism. Produsing theory in a digital world: The intersection of audiences and production in contemporary theory, 80(2012), 15-32.

[30] Oeldorf-Hirsch, A., and Sundar, S. S. (2015). Posting, commenting, and tagging: Effects of sharing news stories on Facebook. Computers in human behavior, 44, 240-249.

[31] Sundar, S. S. (2008). The MAIN model: A heuristic approach to understanding technology effects on credibility. Digital media, youth, and credibility, 73100.

[32] McCracken, G. (1989). Who is the celebrity endorser? Cultural foundations of the endorsement process. Journal of consumer research, 16(3), 310-321.

[33] Fishbein, M. and Ajzen, I. (1975), Belief, Attitude, Intention and Behavior: An Introduction to Theory and Research, Addison-Wesely, Reading, MA (p. 288).

[34] Ahearne, M., Gruen, T. W., and Jarvis, C. B. (1999). If looks could sell: Moderation and mediation of the attractiveness effect on salesperson performance. International Journal of Research in Marketing, 16(4), 269-284.

[35] Yilmaz, C., Eser Telci, E., Bodur, M., and Eker Iscioglu, T. (2011). Source characteristics and advertising effectiveness: The roles of message processing motivation and product category knowledge. International Journal of Advertising, 30(5), 889-914.

[36] Amos, C., Holmes, G., and Strutton, D. (2008). Exploring the relationship between celebrity endorser effects and advertising effectiveness: A quantitative synthesis of effect size. International journal of advertising, 27(2), 209-234.

[37] Lord, C. G., Ross, L., \& Lepper, M. R. (1979). Biased assimilation and attitude polarization: The effects of prior theories on subsequently considered evidence. Journal of Personality and Social Psychology, 37, 2098-2109.

[38] Wojcieszak, M. E., Baek, Y. M., \& Carpini, M. X. D. (2010). Deliberative and participatory democracy? Ideological strength and the processes leading from deliberation to political engagement. International Journal of Public Opinion Research, 22(2), 154-180.

[39] Ajzen, I. (1991). The theory of planned behavior. Organizational Behavior and Human Decision Processes, 50(2), 179-211.

[40] Gagné, M. (2009). A model of knowledge-sharing motivation. Human Resource Management: Published in Cooperation with the School of Business Administration, The University of Michigan and in alliance with the Society of Human Resources Management, 48(4), 571-589.

[41] Shi, Z., Rui, H., and Whinston, A. B. (2013). Content sharing in a social broadcasting environment: evidence from twitter. Available at SSRN 2341243.

[42] FEC 2016 (May 2019) https://www.fec.gov/

[43] Greenwood, S., Perrin, A., Duggan, M., 2016. Social Media Update-2016. Pew Research Center, Washington, D.C.
[44] Cohen, G. L. (2003). Party over policy: The dominating impact of group influence on political beliefs. Journal of personality and social psychology, 85(5), 808.

[45] Bhattacherjee, A., \& Sanford, C. (2006). Influence processes for information technology acceptance: An elaboration likelihood model. MIS quarterly, 805-825.

[46] Sussman, S. W., and Siegal, W. S. (2003). Informational influence in organizations: An integrated approach to knowledge adoption. Information systems research, 14(1), 4765 .

[47] Bock, G. W., Zmud, R. W., Kim, Y. G., and Lee, J. N. (2005). Behavioral intention formation in knowledge sharing: Examining the roles of extrinsic motivators, socialpsychological factors, and organizational climate. MIS quarterly, 29(1), 87-111.

[48] Goode, S., Hoehle, H., Venkatesh, V., \& Brown, S. A. (2017). User compensation as a data breach recovery action: An investigation of the Sony PlayStation Network breach. MIS Quarterly, 41(3).

[49] Segars, A. H. (1997). Assessing the unidimensionality of measurement: A paradigm and illustration within the context of information systems research. Omega, 25(1), 107-121.

[50] Fornell, C., \& Larcker, D. F. (1981). Structural equation models with unobservable variables and measurement error: Algebra and statistics.

[51] Kahai, S. S., \& Cooper, R. B. (2003). Exploring the core concepts of media richness theory: The impact of cue multiplicity and feedback immediacy on decision quality. Journal of management information systems, 20(1), 263-299.

[52] Hair Jr, J. F., Anderson, R. E., Tatham, R. L., \& Black, W. C. (1995). Multivariate Data Analysis, 3rd eds.

[53] Lindell, M. K., \& Whitney, D. J. (2001). Accounting for common method variance in cross-sectional research designs. Journal of applied psychology, 86(1), 114.

[54] Fenigstein, A., Scheier, M. F., \& Buss, A. H. (1975). Public and private self-consciousness: Assessment and theory. Journal of consulting and clinical psychology, 43(4), 522.

[55] Sherer, M., Maddux, J. E., Mercandante, B., PrenticeDunn, S., Jacobs, B., \& Rogers, R. W. (1982). The self-efficacy scale: Construction and validation. Psychological reports, 51(2), 663-671.

[56] Cialdini, R. B., \& Cialdini, R. B. (2007). Influence: The psychology of persuasion (pp. 173-174). New York: Collins.

[57] Venkatesh, V., Brown, S. A., and Bala, H. (2013). Bridging the qualitative-quantitative divide: Guidelines for conducting mixed methods research in information systems. MIS quarterly, 21-54.

[58] Roberts, David. 2017 https://www.vox.com/policy-andpolitics/2017/3/22/14762030/donald-trump-tribal-epistemology [59] John, L. K., Acquisti, A., \& Loewenstein, G. (2010). Strangers on a plane: Context-dependent willingness to divulge sensitive information. Journal of consumer research, 37(5), 858 [60] Hu, P. J. H., Brown, S. A., Thong, J. Y., Chan, F. K., \& Tam, K. Y. (2009). Determinants of service quality and continuance intention of online services: The case of eTax. Journal of the American Society for Information Science and Technology, 60(2), 292-306. 